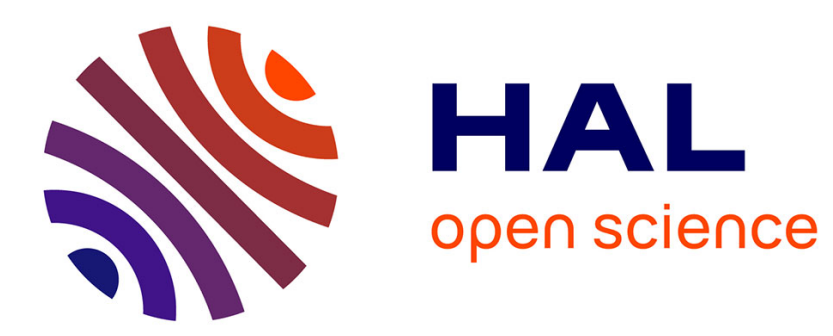

\title{
Experimental Substantiation of Cracked Parts Dynamic Failures Diagnostics
}

\author{
A. Roytman, T. Bychenko
}

\section{To cite this version:}

A. Roytman, T. Bychenko. Experimental Substantiation of Cracked Parts Dynamic Failures Diagnostics. Journal de Physique IV Proceedings, 1997, 07 (C3), pp.C3-181-C3-183. 10.1051/jp4:1997333 . jpa-00255490

\section{HAL Id: jpa-00255490 https://hal.science/jpa-00255490}

Submitted on 1 Jan 1997

HAL is a multi-disciplinary open access archive for the deposit and dissemination of scientific research documents, whether they are published or not. The documents may come from teaching and research institutions in France or abroad, or from public or private research centers.
L'archive ouverte pluridisciplinaire HAL, est destinée au dépôt et à la diffusion de documents scientifiques de niveau recherche, publiés ou non, émanant des établissements d'enseignement et de recherche français ou étrangers, des laboratoires publics ou privés. 


\title{
Experimental Substantiation of Cracked Parts Dynamic Failures Diagnostics
}

\author{
A.B. Roytman and T.A. Bychenko
}

Zaporozhye State University, Department of Mathematics, Zaporozhye, GSP-41, ul. Zhukovskogo 66, Ukraine

\begin{abstract}
The purpose of the research is searching for ways preliminary revealing the moment of macrocracks origination while testing samples and details for fatigue limit with the help of asymmetry of oscillation cycles, at an appropriate excitation duty, exceeding in accuracy the failure criterion being used nowadays.
\end{abstract}

Résumé : Le bui du travail est de trouver les phénomenes précurseurs des microfissures de fatigue par une méthode utilisant des cycles d'oscillation assymétriques. dans un régime excitation excédant les criteres de destruction actuellement utilisés.

Flat metal samples as sufficiently approximating the shape of blade foil of gas turbine engine were chosen as object for the research. Samples were made of titanium alloy and different types of steel. The hypothesis about asymmetry cycle of specimens and products oscillations in case of origination and development of fatigue creck was used as the basic for realized searching investigations. The article with a crack has different longitudinal and compression rigidity, i.e.it is non-linear object. That is way its forced oscillations will differ from harmonic ones. The method of creck revealing. is plotted with the use of this distinctions. With small dimensions of the crack comparing it with dimensions of an article forced vibrations of the article will little differ from vibrations of the article without a crack. Expansion of there vibrations into Furrier's series proved that the first harmonics was close to sole harmonics of vibration of the article without crack but as opposed to that last case higher harmonics caused by distorted one in comparison with harmonic shape of vibrations will come into being. The presence of such harmonics that is the criterion of crack dimensions; comparing the amplitude of the second harmonic with the amplitude of the first one it is possible to esmitate approximately relative dimensions of a crack.

We have: $\frac{b_{2}}{b_{1}} \approx \frac{1}{3} \cdot \frac{\omega_{2}^{2}}{\omega^{2}}=\frac{1}{3} \cdot \frac{c_{2}}{c} ;$

i.e. harmonic ratio for the second and first harmonics is approximately the same as the rigidity ratio $C_{2}$ and $C_{1}$ and hence the ratio of the crack length to the article size in a direction of a crack. Received ratios adaptable to free vibrations of the model with their associated natural oscillations of the initial article one at a time of its phase oscillations. Forced oscillations at a frequency of excitation force approximating any frequency of natural oscillation will occur at it's own appropriate phase. That's why the ratio (1) will be true for forced oscillations as well, close to any resonance duty.

The following basic parameters of vibration were used:

mean root square value of summed level of vibroaccelaration

$$
\widetilde{a}=\sqrt{\frac{1}{T} \cdot \int_{0}^{T} a^{2}(t) \cdot d t}
$$

where $\mathrm{a}(\mathrm{t})$-variations of vibroaccelaration with time, $\mathrm{t} . \mathrm{m} \cdot \mathrm{s}^{-2}$

T-time of averaging,s;

mean root square value of the level of vibroaccelaration at $f$ trequency 


$$
\widetilde{a}=\sqrt{\frac{1}{T} \cdot \int_{0}^{T} a_{\Delta f}^{2}(t) \cdot d t}
$$

where $a_{\Delta f}(t)$-variations of vibroaccelaration with time $t$ in a frequency band $\Delta f$ with meangeometric frequency $\mathrm{f}, \mathrm{m} \cdot \mathrm{s}^{-2}$

Resonance oscillation of the sample produced the emergence of electrical signal in induction converted which by phase, frequency and amplitude followed the character of sample vibrations. The signal from converted (pick-up) was delivered to vibration and noise gauge BLIB - 003,reed-frequency meter 43 - 32 and observed on the screen of oscillograph CI - 83. Rezonance oscillations of sample wers attained by changing the frequency of oscillation of the vibrostand,BЭDC - 1550 vibrator. For more accurate response of the gauge of pulse duration in fruquency meter 43 - 32 sinusoidal signal from the gauge was transformed into trapezoidal with steep front.

Parameters being controlled:

pulse duration $\Pi, \tau_{1}$ mcsec;

pulse duration $\amalg, \tau_{2}$ mcsec.

Parameters being computed average value of pulse duration $\prod_{\tau_{1 \cdot m e r}}$, mcsec;

average value of pulse duration $\amalg_{\tau_{2 n a t}}$, mcsec;

coefficient of cycle asymmetry $R=\frac{\tau_{\text {laver }}}{\tau_{2 \text { aver }}}$.

Typical observation results are shown in Fig1. Results analyses make it possible to emphasize the following.

- Duration of positive $\tau_{1}$ and negative $\tau_{2}$ pulses is significantly different.

- After little changes at initial stage of testing (running-in stage) natural freguency of sample oscillation (resonance frequency) and coefficient of cycle asymmetry remain constant, what is in line with incubation period of creck origination (stage I and II).

- Following 45 minutes testing small variations in resonance frequency of oscillation and modest increases in the coefficient of cycle asymmetry was observed and it is likely that this is related to disintegration of material and origination of macrockacks ( stage III).

- Gradual decrease of frequency of natural oscillations and sadden variations of the coefficient of cycle asymmetry try points to the fact of origination and propagation of the macrocrack (stage IV).

- Following 80 minutes testing catastrophic sample failure began supported by external characteristic: (sound changing,difficulties in supporting resonance sample oscillations ) and readings of the instruments (sudden decrease of natural frequency of oscillations ).

- Of particular interest is the splash on a diagram of variation of the coefficient of asymmetry cycle at the beginning of the stage of macrocrack propagation and which may serve as a diagnostic indication of the onset of macrocrack propagation and what requires further ckecking.

Samples of there types made of chilled steel used for manufacturing rotor blades of gas turbine aviation engines were used.

Samples design is presented in figures 3 a,b,c.

25 samples type "a" with stress concentrator sited near pinching, 25 samples type "b" without stress concentrators, symmetrical relatively neutral axis, 30 samples type "c" without stress concentrators. asymmetrical relatively neutral axis were tested. 
Sample $Q 6 \mathrm{~mm}$ (steel 20)

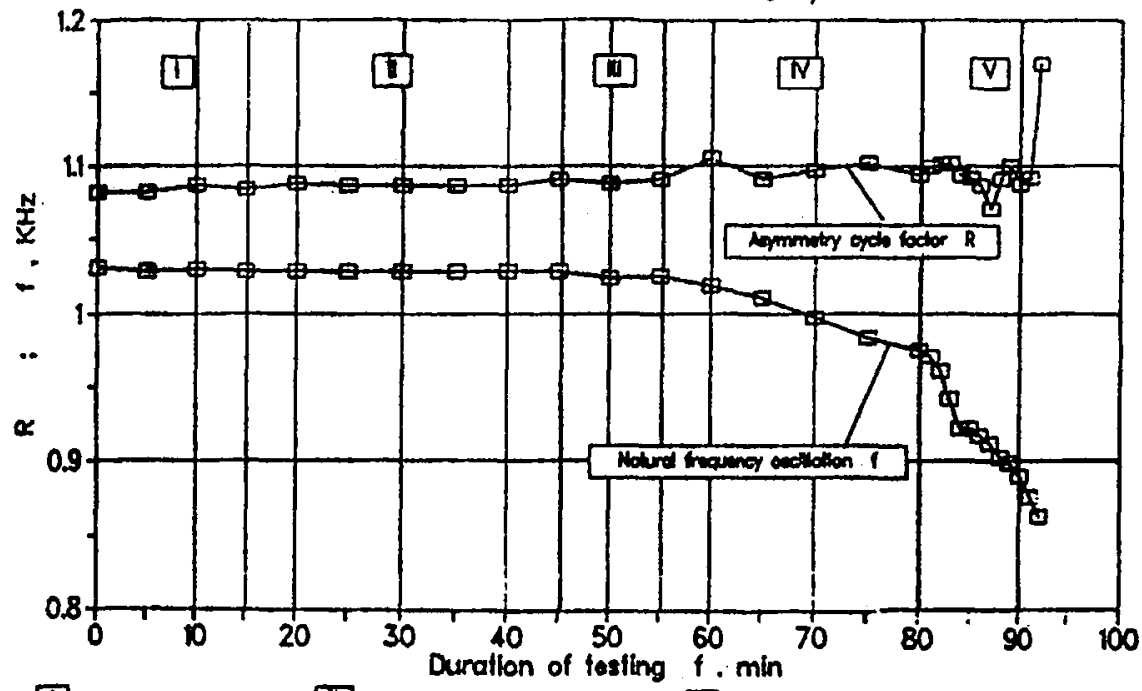

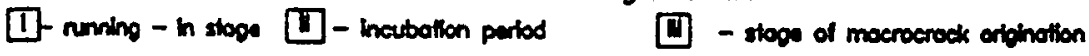
[V] - stope of macrocrock dembopment $V$ - stoos of cotostrophic tollun

Figure 1. Variations in natural frequence oscillation and asymmetry cycle factor.
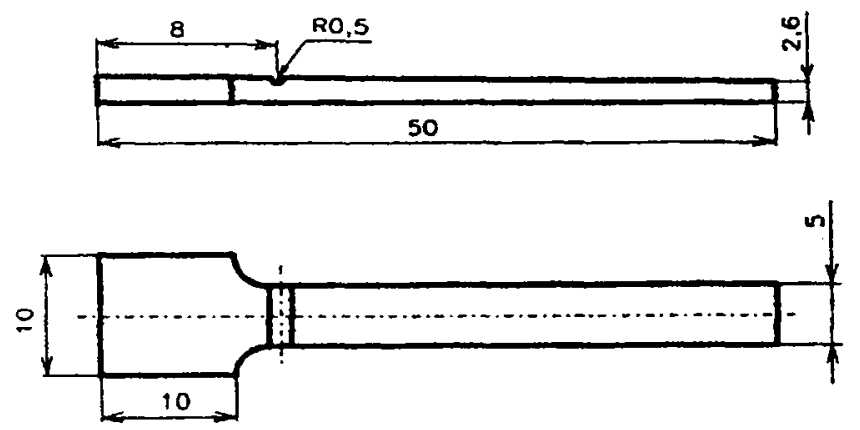

a)

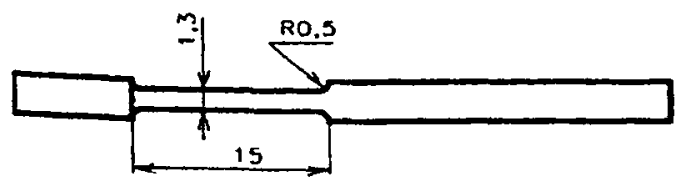

b)

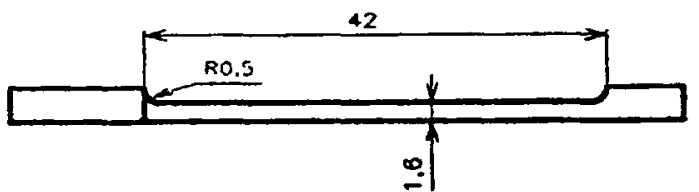

c)

Figure 2. 